\title{
Information literacy in the workplace
}

\section{CILIP Conference}

Information literacy and digital inclusion

Thursday 2 July $2015-11: 15$

Dr Charles Inskip

c.inskip@ucl.ac.uk 


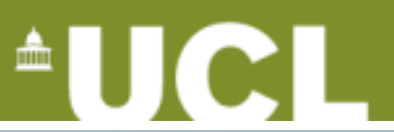

$\sin$

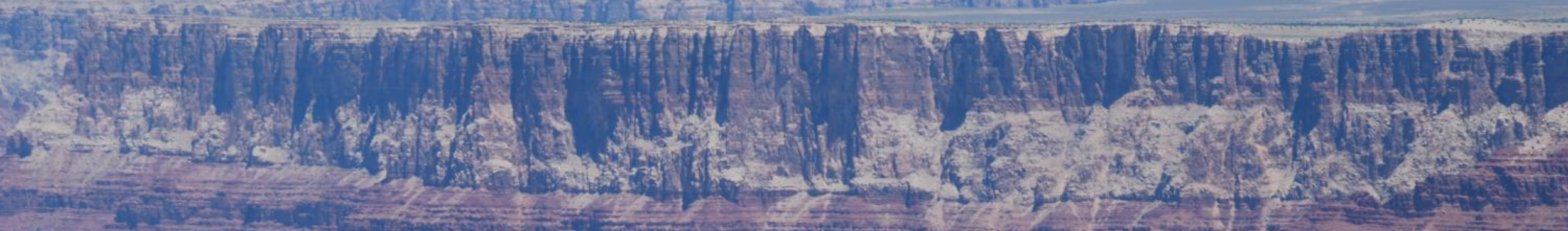

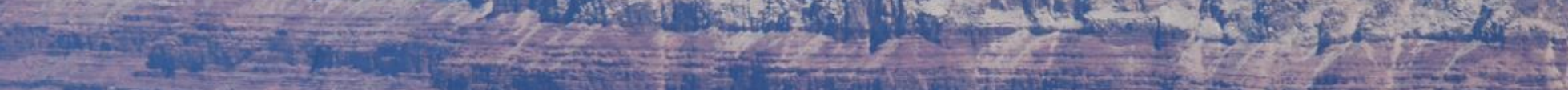

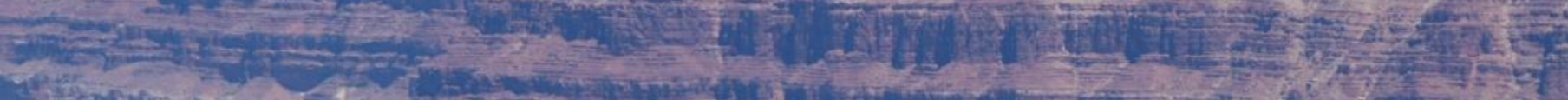
ring

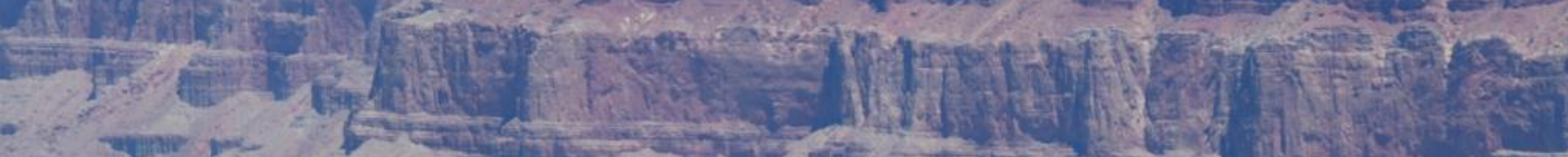

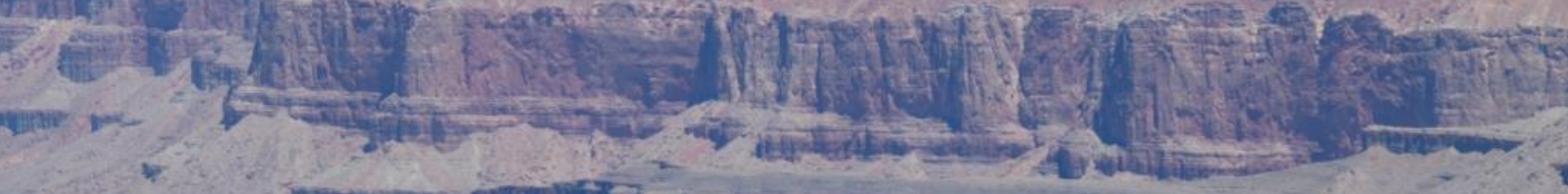

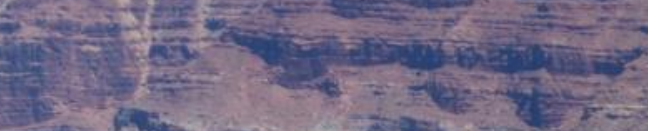

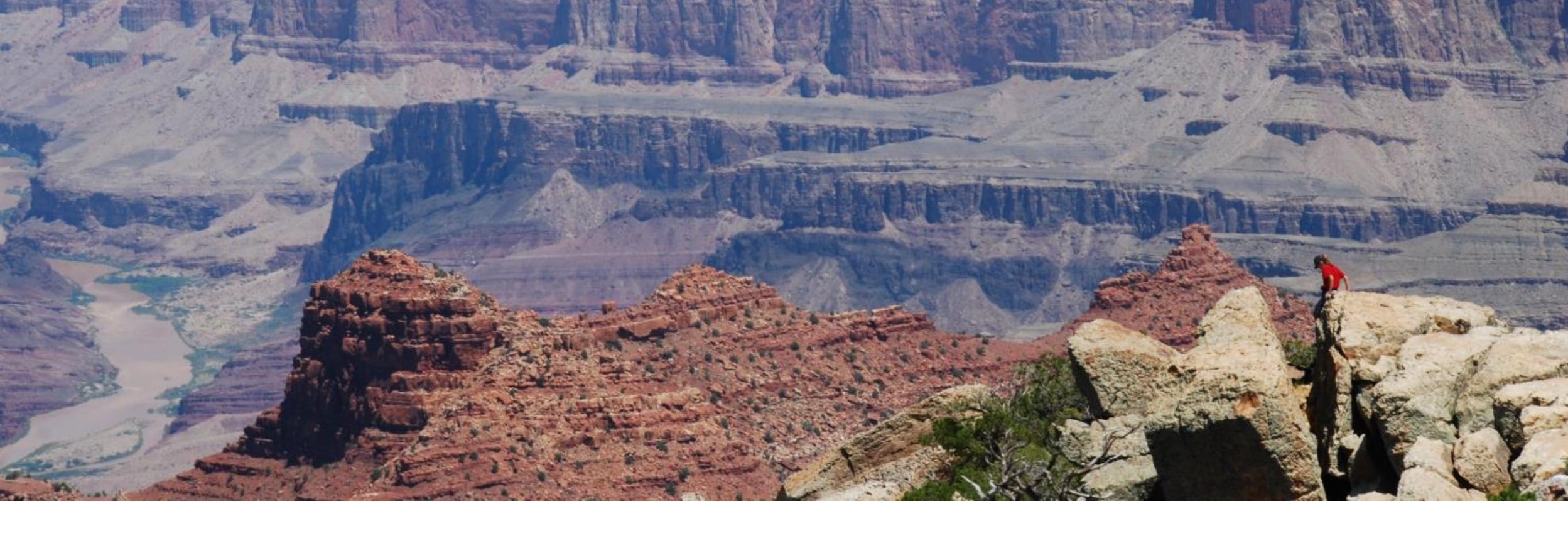




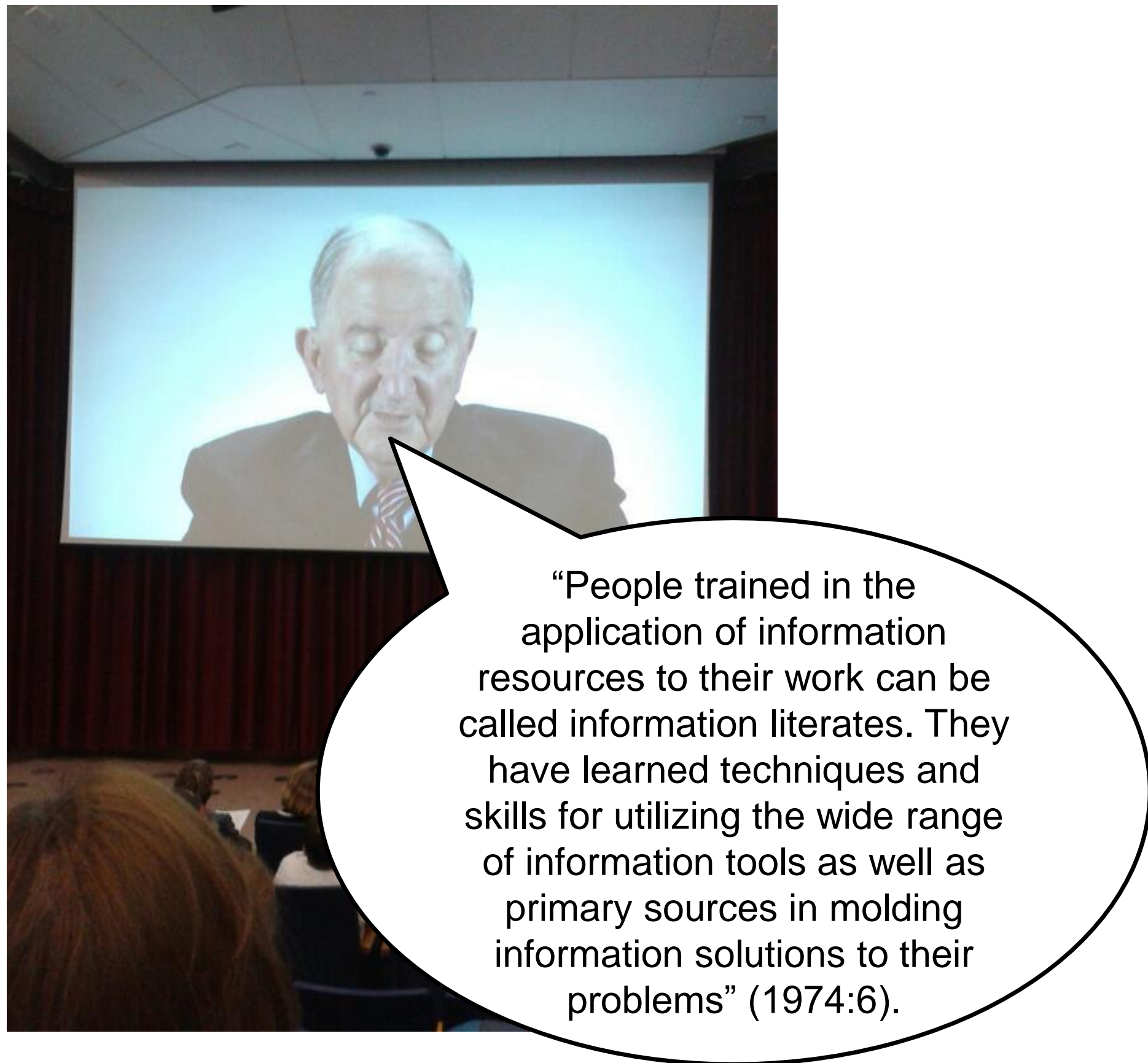




\section{$\pm J C_{L}$}

\section{Information literacy}

empowers pe

of life

and $c$ edUCATIONAL ration

effecti

e in all walks

e, use

their

occupational and educational analc It ic a hacin human 


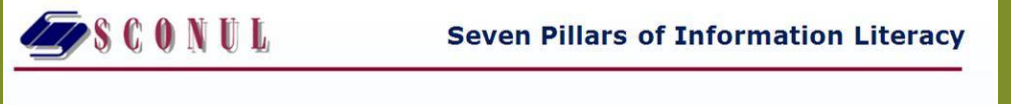

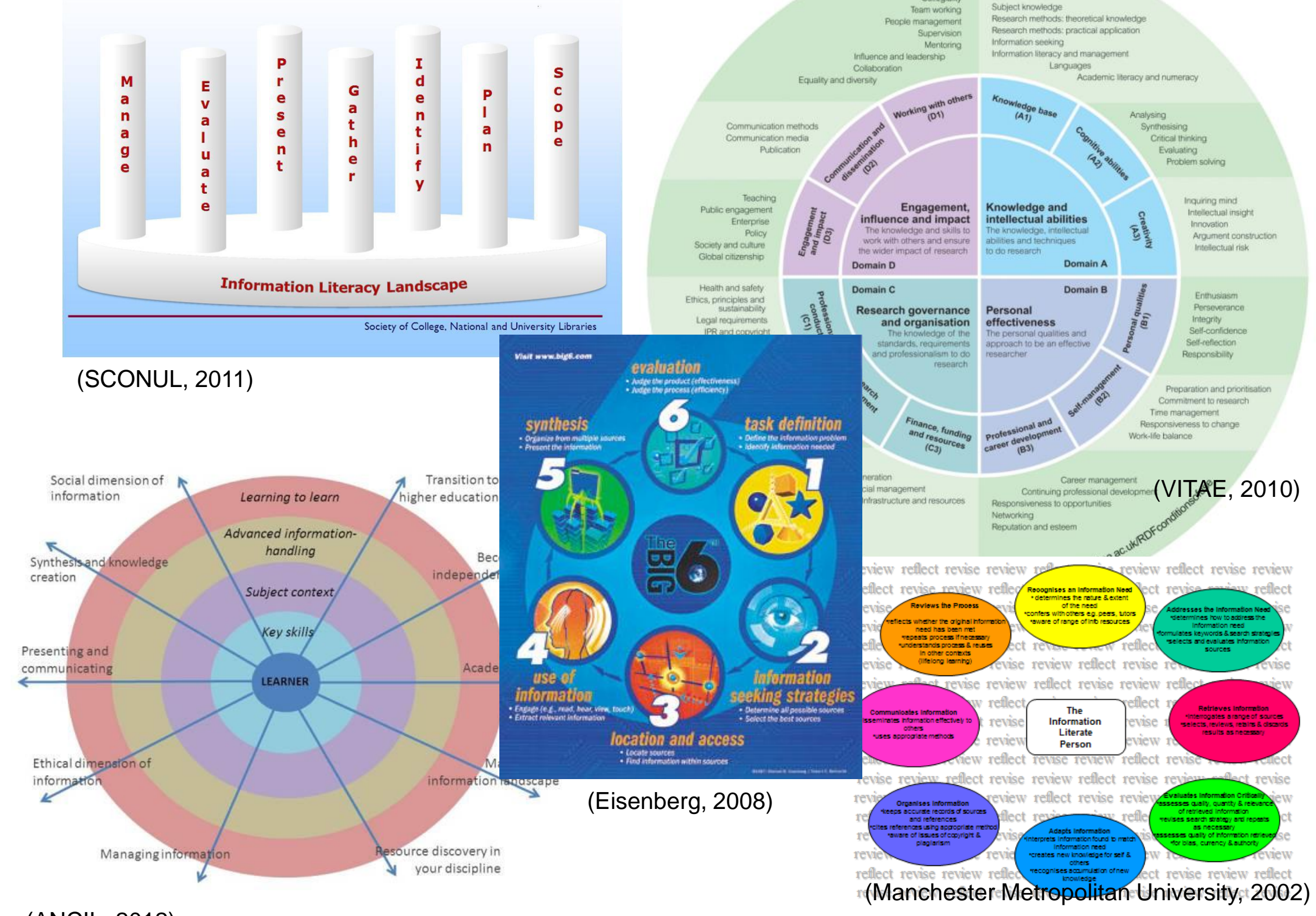

(ANCIL, 2012) 


\section{$\stackrel{ \pm}{\prime} / C L$}

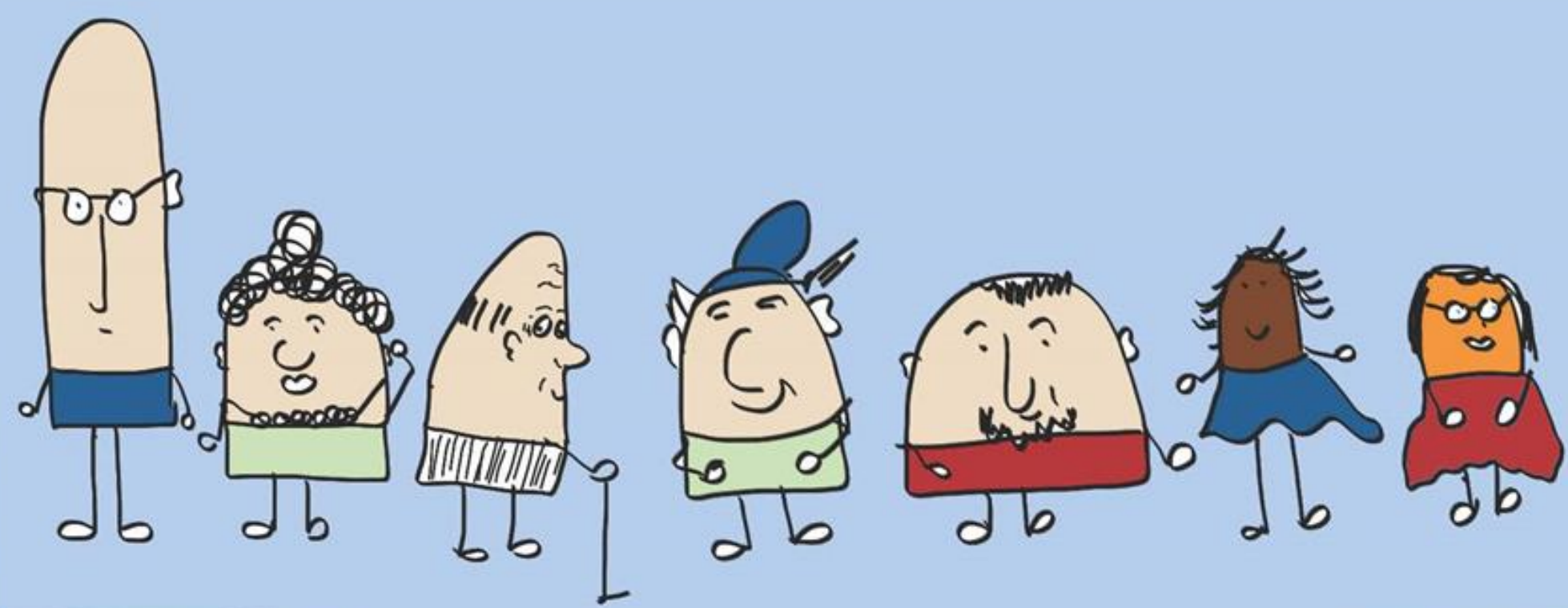

Image: Tanja Fohr Flickr (CC BY-NC-SA 2.0)
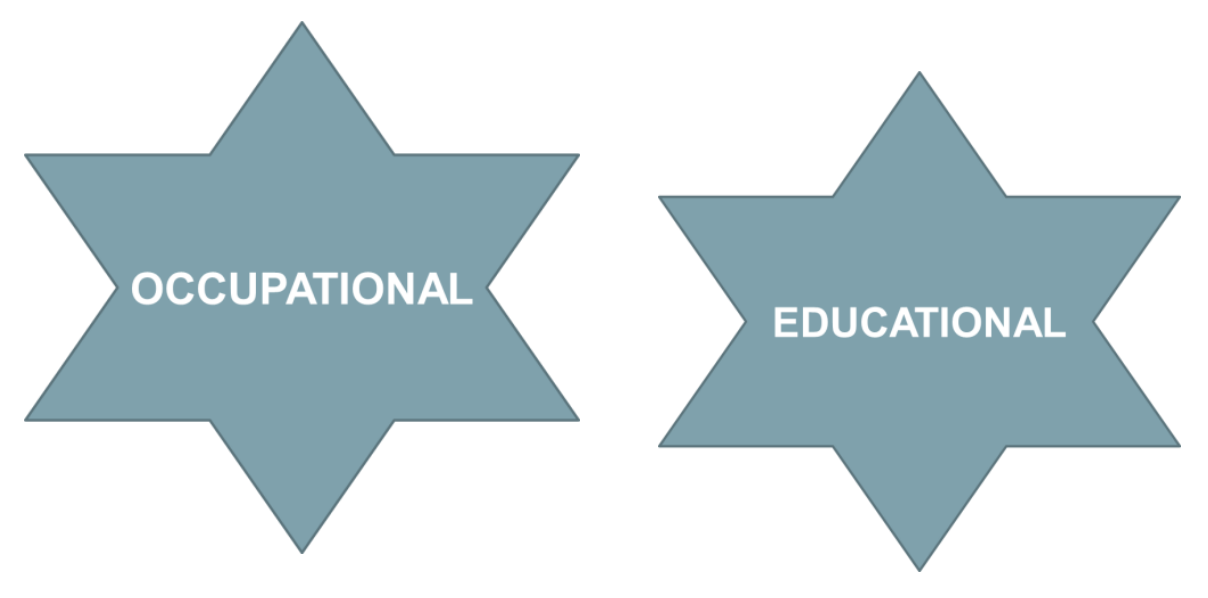


\section{$11 m$ lack digital skills}

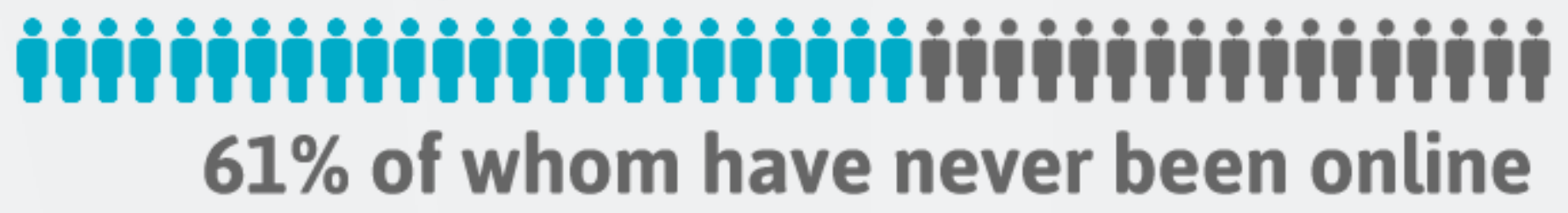

That makes the work UK online centres do at a grassroots level vital in closing the digital divide, and levelling the playing field for all.
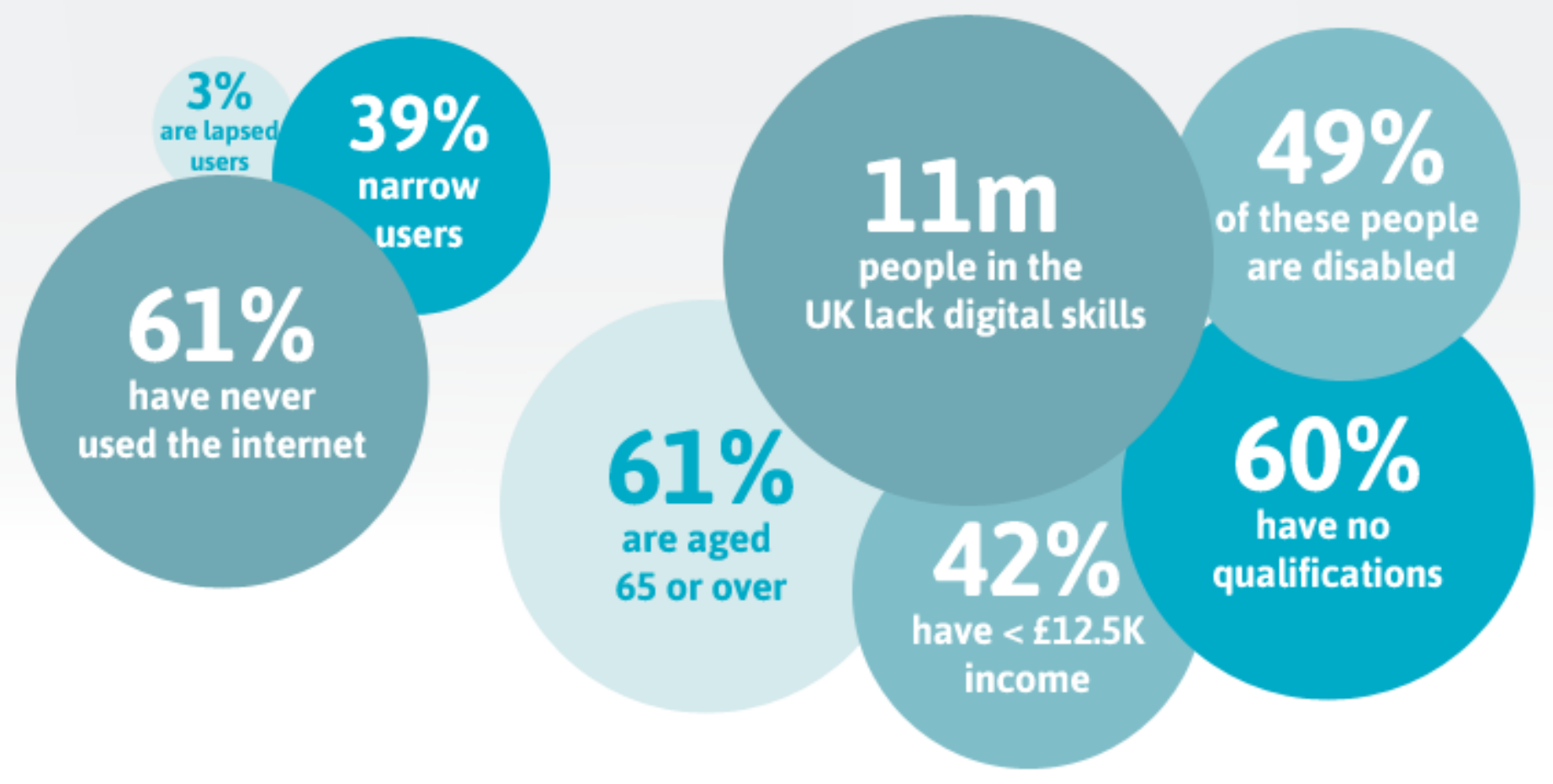

http://www.ukonlinecentres.com/about-us/digital-inclusion 


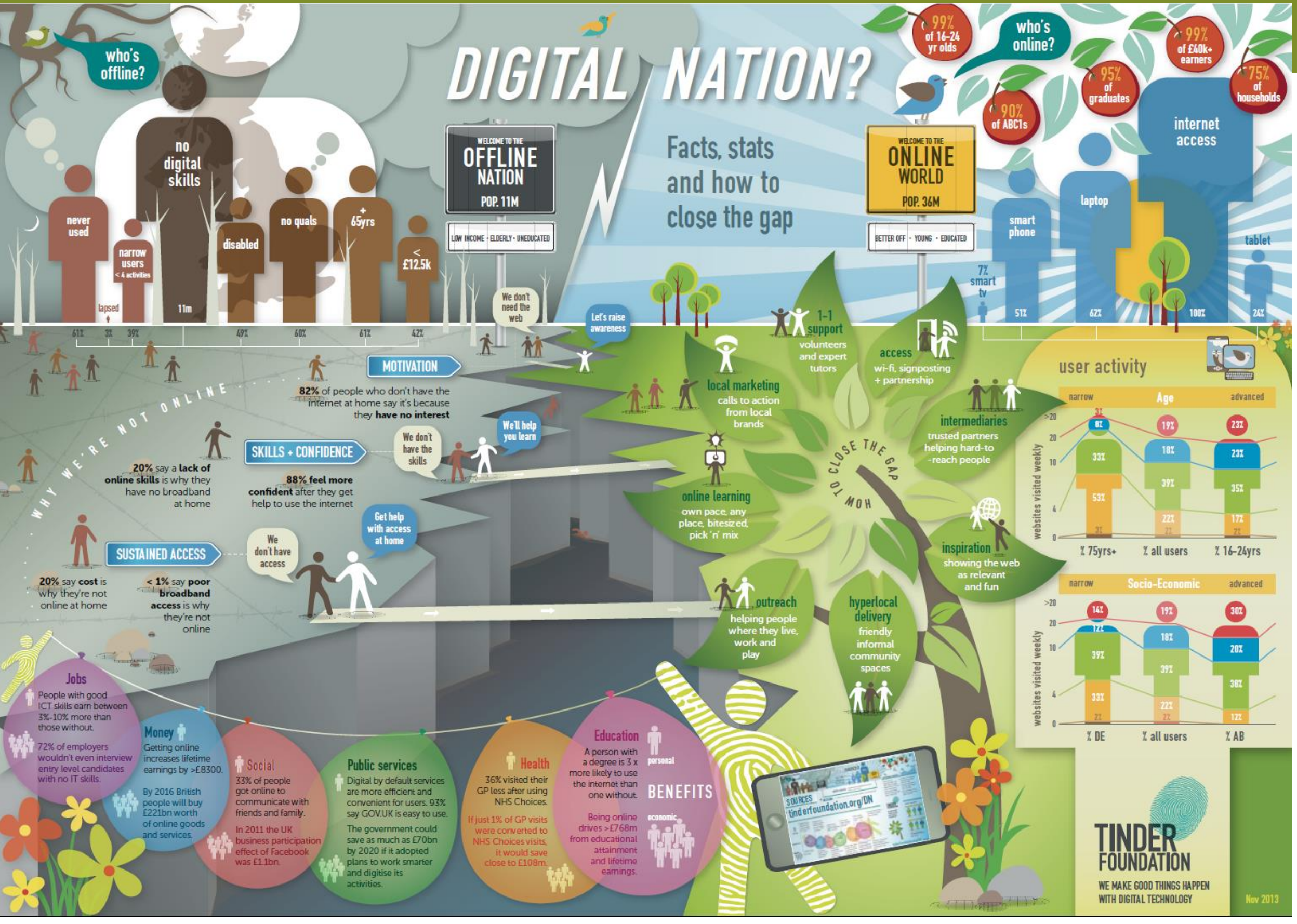

http://www.tinderfoundation.org/sites/default/files/research-publications/digital nation infographic.pdf 


\section{"... over a third of British businesses don't even have a website"}

\section{BRITAIN'S DIGITAL OPPORTUNITY}

\section{A STUDY OF DIGITAL MATURITY WITHIN BRITAIN'S BUSINESSES AND CHARITIES.}

"By engaging with SMEs during the early stages of digital development, reinforcing positive messages about growth and signposting them to relevant services, there is an opportunity to accelerate momentum amongst this group." 


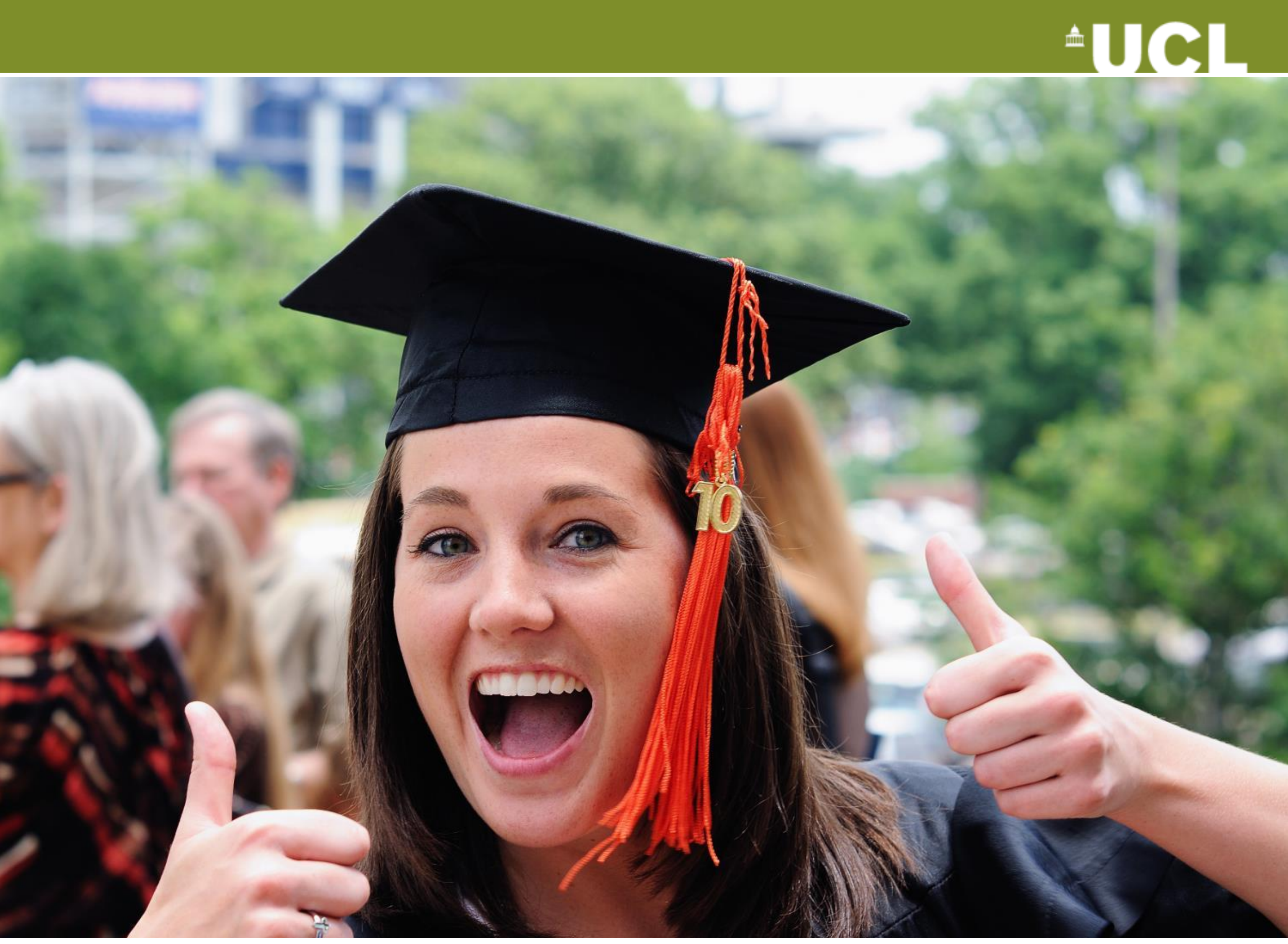




\section{Useful recent documentation}

- Transferring information know-how

- Information Literacy in the

Workplace: An annotated bibliography

- Information literacy is for life, not just for a good degree: a literature review

- Digital skills for tomorrow's world

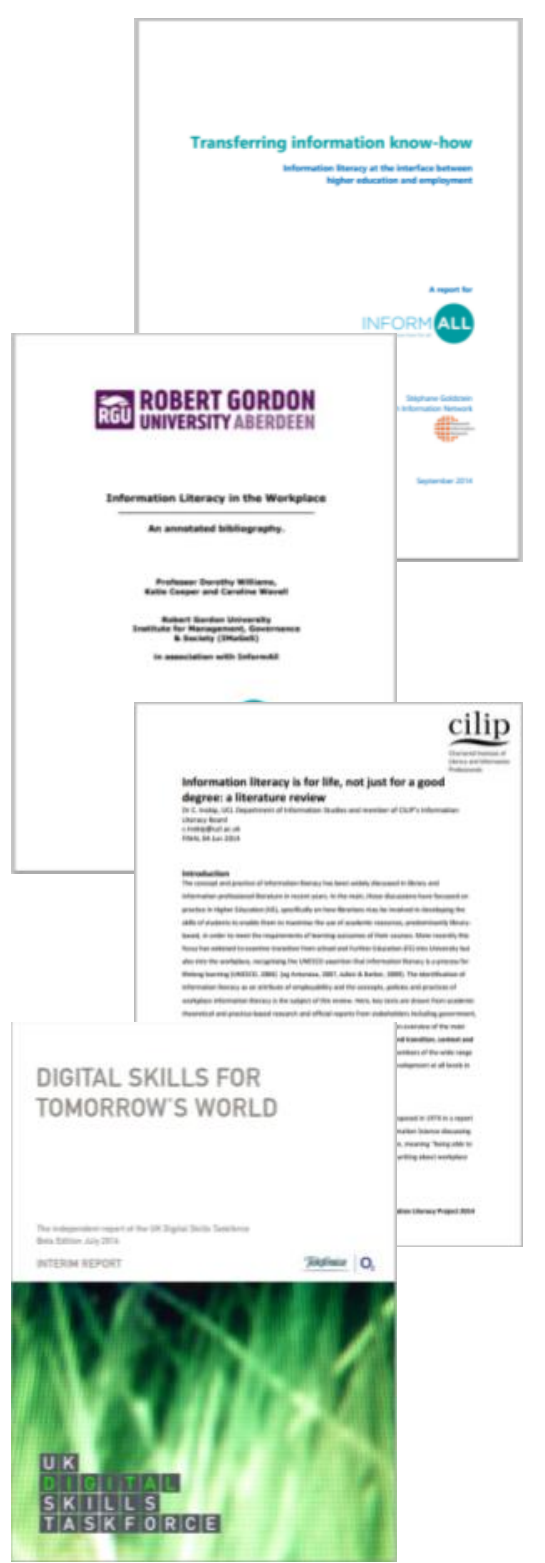




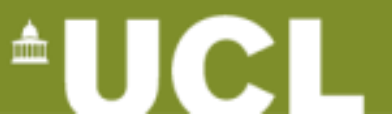

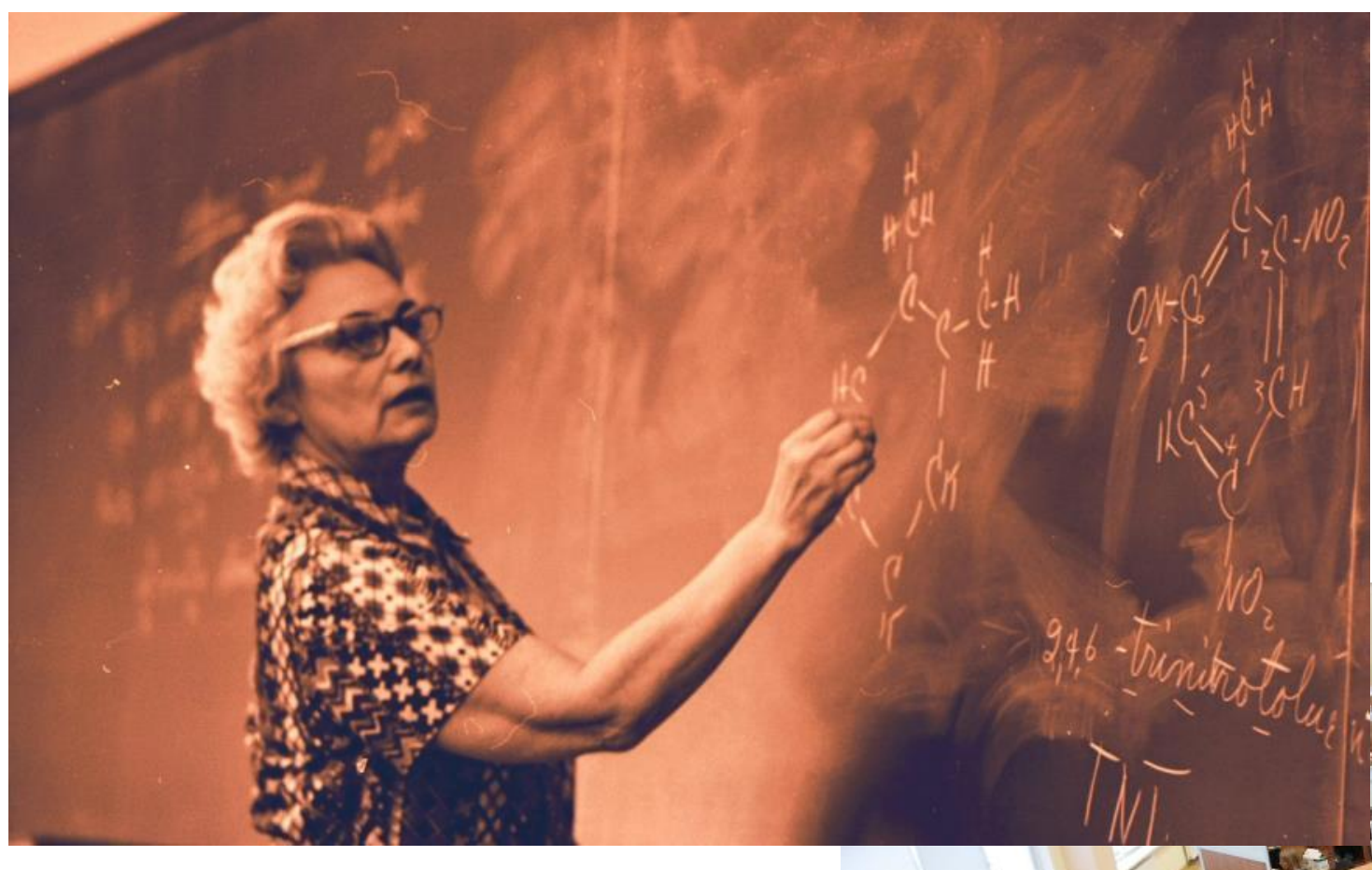

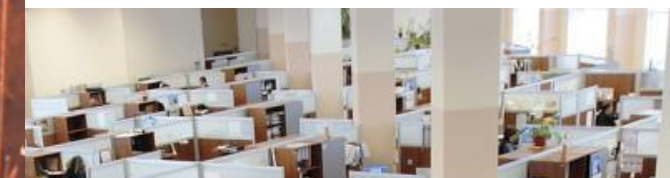

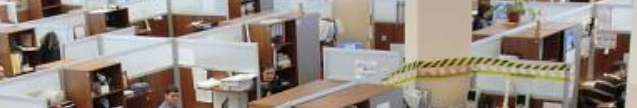

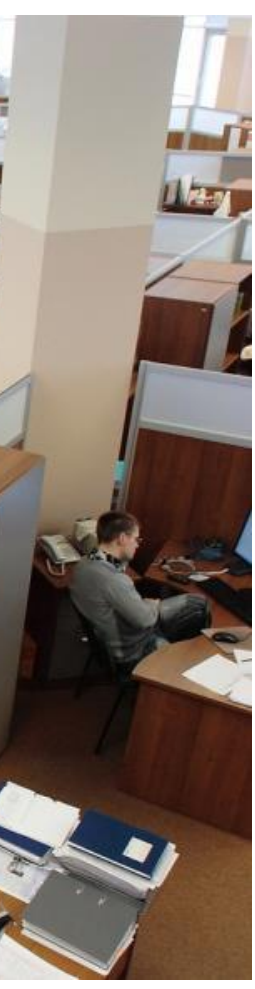

Russia, Office, Men, Women, Working, Workers, Complex - tpsdave - http://pixabay.com/en/russia-office-men-women-working-95311/ CC0 1.0 


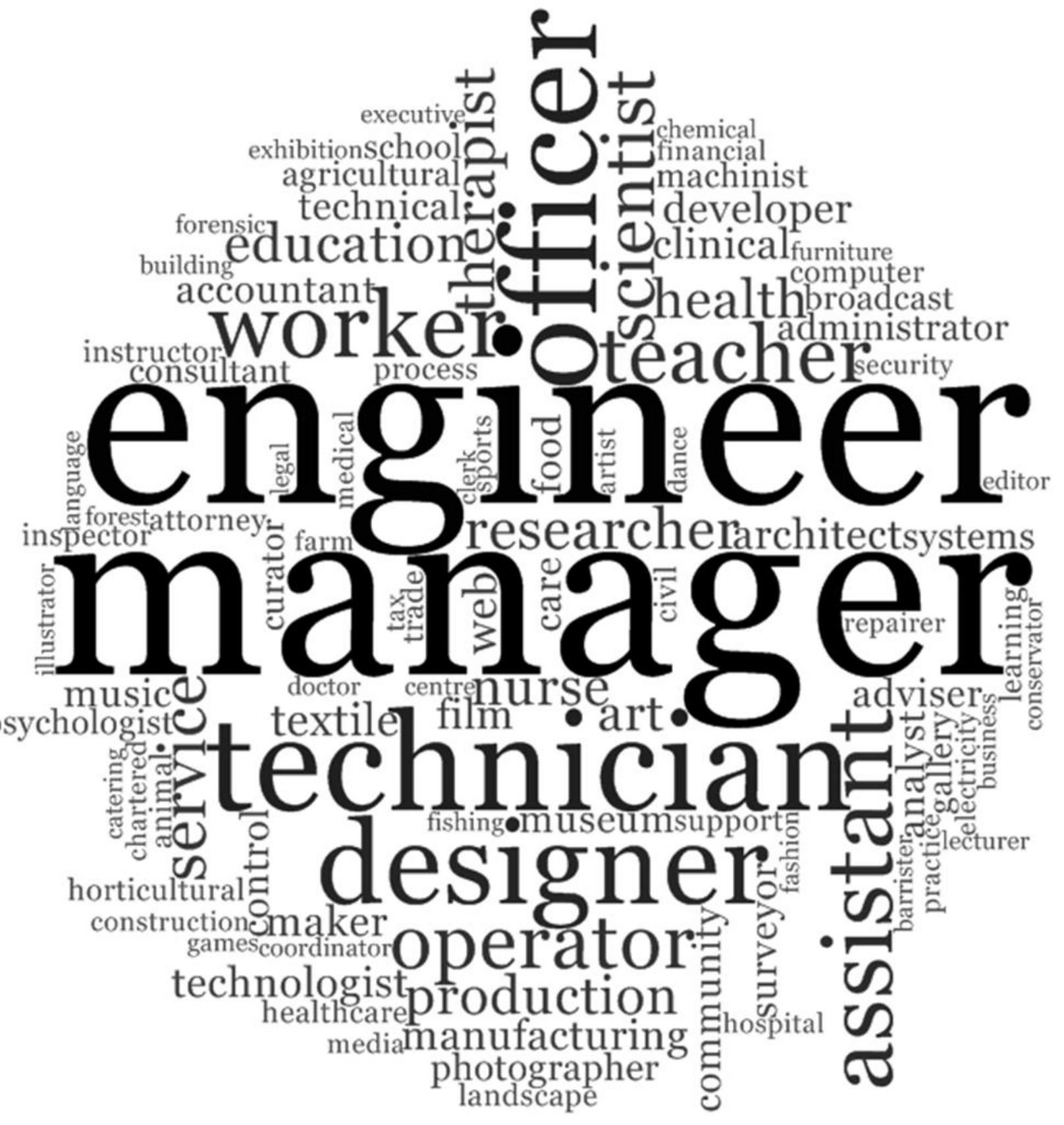




\section{LITERACY}

\section{WORKPLACE}

digital ict

computing

data media research

problem-solving current awareness knowledge-management e-skills skills fluency competencies capabilities abilities solving awareness understanding evaluation know-how knowledge confidence

capacity use handling reports presentations plans copyrights confidentiality instructions weights measures up-to-date 19 GaUtion WORK IN
PROGRESS 


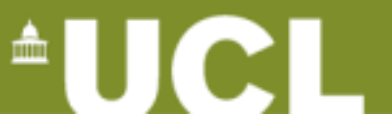

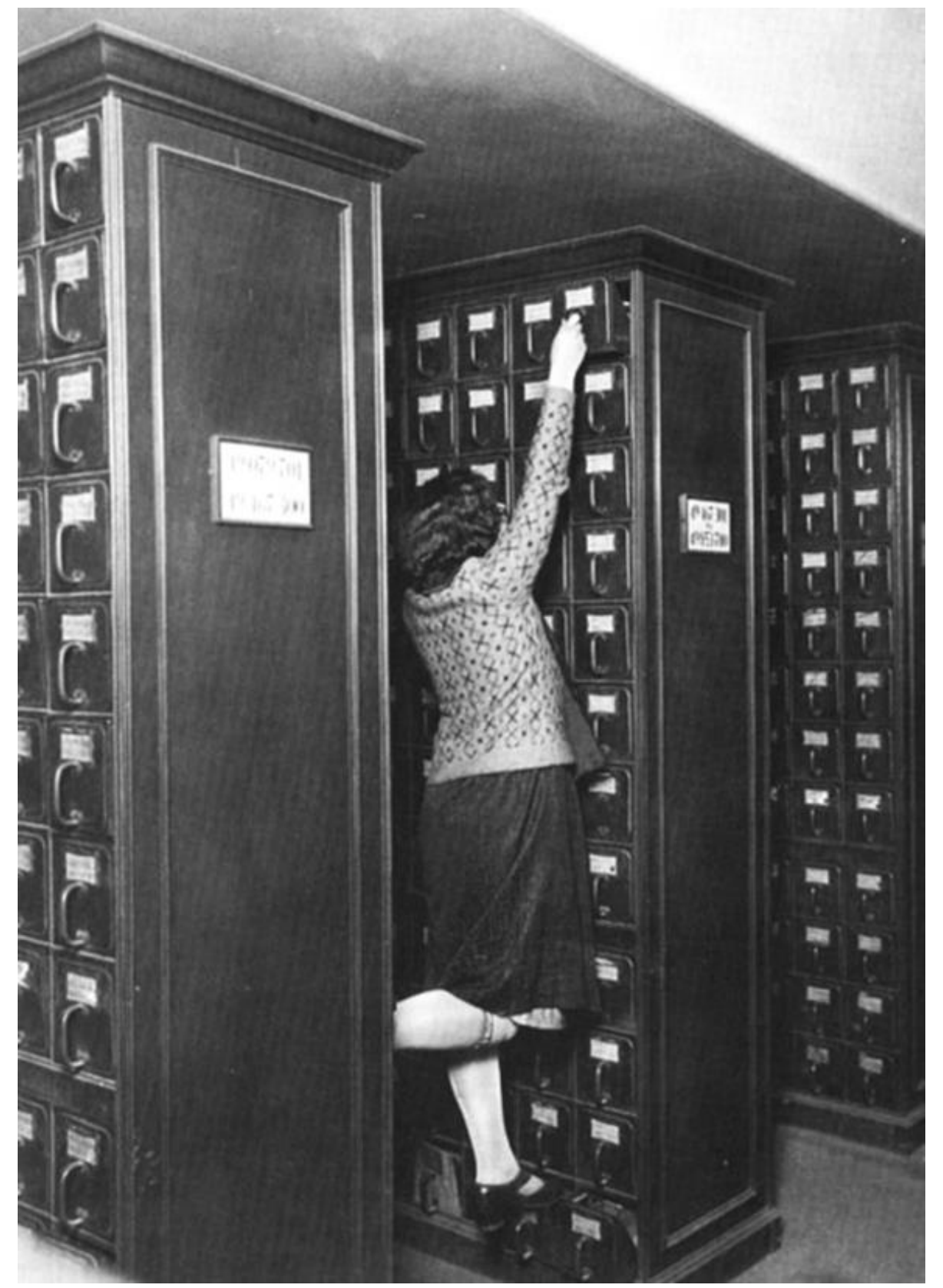




\section{$\stackrel{=}{ }{ }^{\prime} C L$}
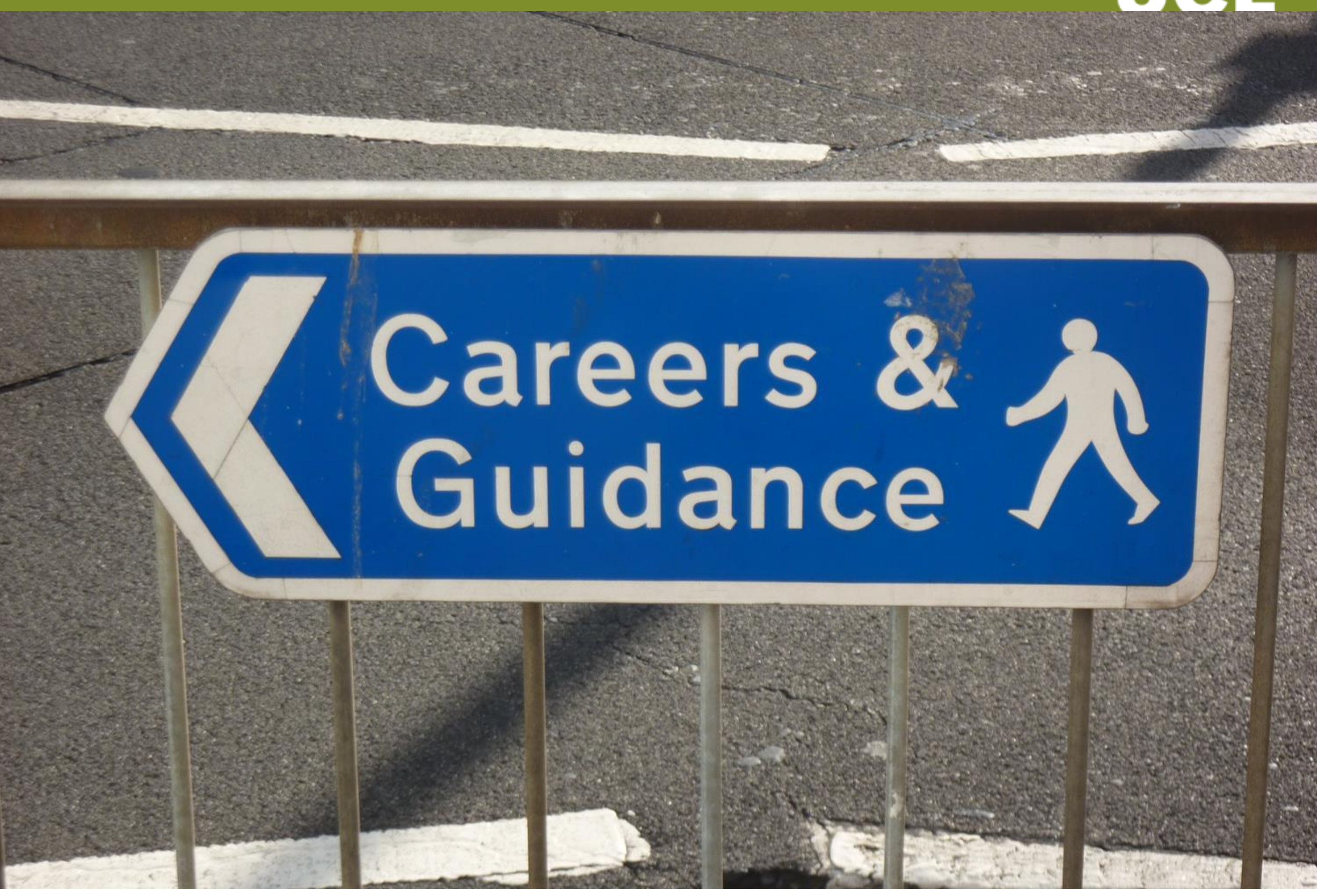


\section{$\stackrel{ \pm}{ }=$}

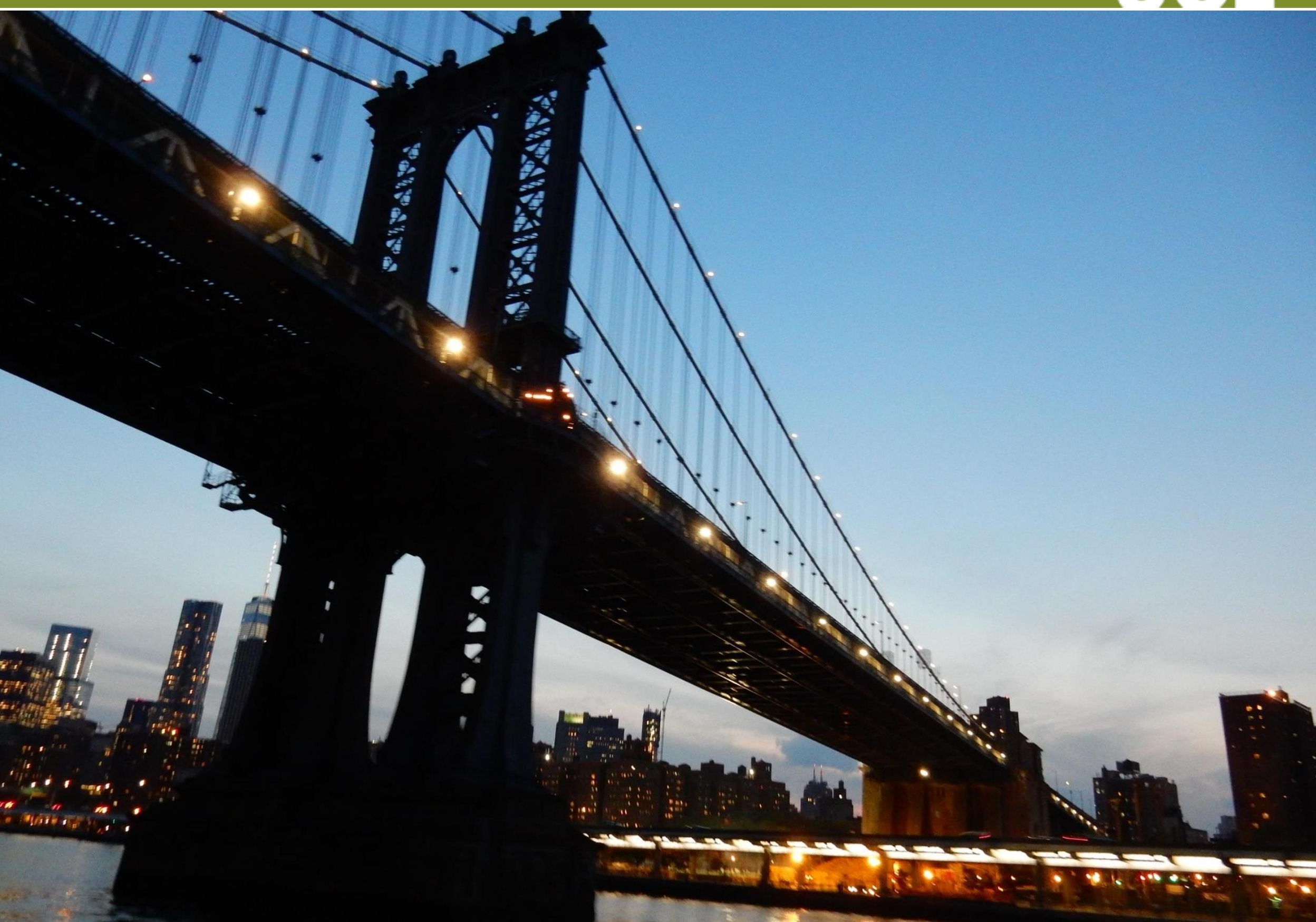


